\title{
pDNA Capture Using Grafted Adsorbents
}

\author{
Naveen Kumar Singh ${ }^{1,2}$, Roy N. Dsouza ${ }^{3}$, Vikas Yelemane ${ }^{1}$, Nina Nentwig ${ }^{1}$, Mariano \\ Grasselli $^{4}$ and Marcelo Fernández-Lahore ${ }^{1 *}$ \\ ${ }^{1}$ Downstream BioProcessing Laboratory, Department of Life Sciences \& Chemistry, Jacobs \\ University, Campus Ring 1, D-28759 Bremen, Germany \\ ${ }^{2}$ Bruening Lab, Department of Chemical \& Biomolecular Engineering, University of Notre \\ Dame, Notre Dame, 46556 Indiana, USA \\ ${ }^{3}$ Chemistry Lab, Department of Life Sciences \& Chemistry, Jacobs University, Campus Ring \\ 1, D-28759 Bremen, Germany \\ ${ }^{4}$ Laboratorio de Materiales Biotecnológicos, Depto. de Ciencia y Tecnología, Universidad \\ Nacional de Quilmes, Roque Sáenz Peña 352 (B1876BXD) Bernal, Argentina
}

*Correspondence to:

Prof. Dr. Marcelo Fernández-Lahore,

Downstream BioProcessing Laboratory, Jacobs University, Campus Ring 1, D-28759 Bremen, Germany.

This article has been accepted for publication and undergone full peer review but has not been through the copyediting, typesetting, pagination and proofreading process which may lead to differences between this version and the Version of Record. Please cite this article as doi: $10.1002 /$ jctb.5671 
Phone: +49 421200 3239,

Fax: +49 4212003600 .

E-mail: m.fernandez-lahore@jacobs-university.de 


\begin{abstract}
BACKGROUND. "Expanded" composite materials are of interest as an alternative, or as a supplement, to packed-bed chromatography during bioproduct recovery and purification. Functionalized non-woven fabrics and mega-porous bodies are examples of systems that showed promise. However, there is scarce information on their suitability to capture and release plasmid DNA (pDNA), an important type of product employed in gene therapy.

RESULTS. Composite adsorbents were prepared via either chemical (CG-DEAE-NW) or gamma-irradiated graft-polymerization (GIR-DEAE-MP), and subsequently modified to have diethylamino ethanol (DEAE) functionality. Capture experiments showed that pDNA can actually reversibly bind to the two mentioned adsorbents, with capacities values of $2.4 \mathrm{mg}$ per $\mathrm{mL}$ and $1.3 \mathrm{mg}$ per $\mathrm{mL}$, respectively. These values are in the range of what can be expected from commercial beaded adsorbents but lower that the values expected from monoliths.
\end{abstract}

CONCLUSIONS. Expanded materials, due to their high voidage, may present a limited capacity for pDNA. However, such materials are able to bind proteins and other contaminants from bacterial lysate, opening the way for their utilization in the "negative" mode.

Keywords: pDNA purification; expanded adsorbents; chromatography; gene therapy. 


\section{Introduction}

Liquid chromatography is the most widely used method for the purification of therapeutic biomolecules (e.g. pDNAs, mRNA, or VLPs) as it provides high product resolution and uses GRAS chemicals. Chromatographic processes can be operated under various conditions, where physical and chemical properties of plasmid DNA can play a significant role in separations. Several chromatographic methods such as anion exchange $(\mathrm{AEX})^{1}$, size exclusion (SEC) ${ }^{2}$, hydrophobic interaction $(\mathrm{HIC})^{3,4}$, reversible phase (RPLC) ${ }^{5}$, triple helix , and boronate affinity chromatography ${ }^{6}$ have been reported for the purification of pDNA. Anion exchange chromatography, while being the most commonly used approach for purifying biomolecules, are poor at resolving pDNA from other nucleic acids that have similar charge density ${ }^{7,8}$. In RNase-free bioprocesses, RNA is found to co-elute with pDNA as there are no other means of RNA reduction used in the upstream processes. Commercial resin-based anion-exchangers suffer from poor binding capacities for plasmid DNA due to small pore sizes $(<30 \mathrm{~nm}$ in diameter), and were initially designed and optimized for the purification of proteins, which exclude pDNA (with a typical hydrodynamic radius around 150-250 nm) from entering the inner pores of resins. Therefore, high capacity adsorbents with convective "superpores" are being developed for the efficient purification of plasmid DNA $^{9-12}$. Several RNase-free bioprocesses based on anion-exchange chromatography have consequently been developed ${ }^{13}$, however, they are rather complex and time-consuming, and need an additional operational unit to accommodate the resulting burden of RNA impurity ${ }^{14}$. Alternatives to packed-bed chromatography have been developed in the last 15 years, and include now a variety of approached that include, but is not limited to functionalized "monolithic" rods 3 , 6, 15-18, (composite) synthetic membranes ${ }^{19,20}$ and (magnetic) micro-tonano particles ${ }^{21}$. All the mentioned systems present comparative advantages and disadvantages. Some techniques are applicable to specific "niches" in the purification of bioproducts. There is room enough for additional developments in the field.

"Expanded" material backbones can be efficiently functionalized to bind a whole range of bioproducts. Larger voidage pores within the structure of the mentioned materials, 
derive in the absence of diffusive mass transport limitations ${ }^{22}$. Such expanded backbones can be manufactured methods like the cryogel-technique, that has been already explored for purification of pDNA. A second approach consists in the production of non-woven fibrous networks, where is active material is provided by the fibers themselves. In principle, such adsorbent systems could accommodate a particle-containing sample or feedstock, therefore facilitating the purification scheme. An additional advantage results from the lack of backpressure during operation. The purification or fractionation of nanoplexes and cells could also be envisioned with such systems. Along this line of thought, the megaporous structure of expanded adsorbent should allow the penetration of large pDNA molecules at high flow rate with low-pressure drops .

Gene therapy involves the transfer of a therapeutic gene into a patient with the objective of either curing a disease or reducing the spread of illness . The effectiveness of gene therapy is based on the vector capable of transferring the therapeutic gene into the target cells. Naked or plasmid DNA vectors are increasingly utilized over the viral vectors as the virus based vectors pose safety and regulatory concerns over their usage for gene therapy . Consequently, there has been a demand for using pDNA as the vector for delivering the therapeutic genes in gene therapy and DNA vaccination. Plasmid DNA vectors have several technical advantages over other conventional vectors, such as low production cost, high product stability, and safety . Plasmids are extra-chromosomal double-stranded circular DNA molecules found in virtually all bacterial species and can replicate autonomously. They have sizes up to hundreds of kilobasepairs $(\mathrm{kb})$ and are found in three forms, namely, supercoiled (SC), open circular (OC) and linear (L). For large-scale production of pDNA, the therapeutic gene is inserted into the appropriate vector and then introduced into a microbial host, most commonly E. coli.

In the present study, we have evaluated the efficacy of anion-exchange (composite) expanded adsorbents to purify pDNA. These adsorbents consist of either non-woven cellulosic fibers or cryogel-type backbones, which were first graft-polymerized with GMA, and subsequently modified via free epoxy groups to have DEAE functionality, where the nitrogen content of the resulting DEAE adsorbents was evaluated using elemental analysis. These adsorbents 
could potentially be integrated with RNase-free downstream bioprocesses for addressing the issues of low capacity, reduced resolution from host impurities (e.g. gDNA and high molecular weight RNA), as well as the high complexity of the overall purification process. For this specific application, the high viscosities of DNA extracts and the low diffusivity characteristic of larger macromolecules introduce severe performance limitations.

\section{Material and methods}

\section{Chemicals and reagents}

Sodium chloride $(\mathrm{NaCl})$, sodium hydroxide $(\mathrm{NaOH})$, ethylenediaminetetraacetic acid (EDTA), and ethidium bromide solution 1\% were purchased from AppliChem GmbH (Darmstadt, Germany). Tris (99.3\%, buffer grade) was purchased from Carl Roth (Karlsruhe, Germany). Buffer P1 "Resuspension Buffer", Buffer P2 "Lysis Buffer", and Buffer P3 "Neutralization Buffer" were purchased from Qiagen (Hilden, Germany). Ethanol absolute was obtained from Honeywell Specialty chemicals Seelze GmbH (Seelze, Germany).

All the buffer solutions were filtered through $0.45 \mu \mathrm{m}$ disposable membrane filters (Sartorius, Goettingen, Germany).

\section{Bacterial culture}

E. coli $\mathrm{DH} 5 \pm$ strain containing a pTurbo GFP plasmid of $4.7 \mathrm{~kb}$ length was generously provided by Generi Biotech (Hradec Králové 11, Czech Republic). The culture was harvested by centrifugation and stored at $-20{ }^{\circ} \mathrm{C}$ until further use.

The bacterial strain was propagated in TB enriched medium (glycerol $13 \mathrm{~g} / \mathrm{L}$, vitamins, yeast extract $24 \mathrm{~g} / \mathrm{L}$, triptone $12 \mathrm{~g} / \mathrm{L}, \mathrm{KH} 2 \mathrm{PO} 42.31 \mathrm{~g} / \mathrm{L}, \mathrm{K} 2 \mathrm{HPO} 412.54 \mathrm{~g} / \mathrm{L}$ ). The inoculum was grown in $0.5 \mathrm{~L}$ Erlenmeyer flasks containing $100 \mathrm{~mL}$ of TB-enriched medium. 
The culture developed in shaking flasks $(240 \mathrm{rpm})$ at $37{ }^{\circ} \mathrm{C}$. The cultures were harvested during the stationary phase. Biomass was followed by turbidimetry $(600 \mathrm{~nm})$. The cell biomass $(20-24 \mathrm{~g} / \mathrm{L}$ wet weight) was harvested by centrifugation and disrupted utilizing a conventional alkaline lysis protocol (see below).

\section{Cell lysis}

Bacteria were lysed using a modification of the alkaline method described previously. Bacterial Cell Lysate (20 g) was re-suspended in $200 \mathrm{~mL}$ of Buffer P1 (50 mM Tris buffer pH 8.0 containing $10 \mathrm{mM}$ EDTA) and then treated with $200 \mathrm{~mL}$ cell lysis buffer P2 (0.2 M $\mathrm{NaOH}$ and $1 \%$ SDS) for $30 \mathrm{~min}$ at $4{ }^{\circ} \mathrm{C}$. The lysate mixture was neutralized with $200 \mathrm{~mL}$ buffer P3 (3 M potassium acetate, adjusted to $\mathrm{pH} 5.0$ with glacial acetic acid and chilled to 4 $\left.{ }^{\circ} \mathrm{C}\right)$. All the precipitated materials including cell debris, most chromosomal DNA and some RNA and proteins were removed by centrifugation at $9000 \mathrm{x}$ g for $10 \mathrm{~min}$ on a Sorvall RC5C Plus (Kendro, Newton, CT) and followed by clarification through a $0.45 \mu \mathrm{m}$ Sartobran $\mathrm{P}$ Filter. A clarified lysate containing pDNA concentration in the range of 24 to $47 \mu \mathrm{g}$ per $\mathrm{mL}$ was obtained; the amount of pDNA was evaluated using a purification commercial kit (QIAGEN, Hilden, Germany) followed by spectrophotometry ((NanoDrop, Wilmington, DE). Before chromatography, the clarified lysate was dialyzed overnight against $10 \mathrm{mM}$ Tris- $\mathrm{HCl}$ buffer ( $\mathrm{pH}$ 8.0) or diluted in the mentioned buffer; this has adjusted the conductivity value of the feedstock $(\approx 15-20 \mathrm{mS} / \mathrm{cm})$.

\section{Preparative chromatography}

The CG-DEAE-fibers and GIR-DEAE Cryogels were sythesized as previously reported $^{9,16,23}$. They were packed in $5.5 \mathrm{~cm} \times 5 \mathrm{~mm}$ and $3.4 \mathrm{~cm} \times 10 \mathrm{~mm}$ columns, respectively (GE Amersham Biosciences, Uppsala, Sweden) and connected to a Äkta Explorer 100 having UNICORN ${ }^{\text {TM }} 4.10$ software (GE Amersham Biosciences, Uppsala, Sweden). The equilibration of AEX adsorbents was carried out with $50 \mathrm{mM}$ Tris, $10 \mathrm{mM}$ EDTA, $200 \mathrm{mM} \mathrm{NaCl}$, pH 7.2 at a flow rate of $300 \mathrm{~cm} / \mathrm{h}$. 200 (GIR-DEAE Cryogel)/400 mL (CG-DEAE fibers) clarified lysate of pTurbo GFP plasmid diluted in equilibration buffer 
(1:10) was loaded onto AEX columns at $300 \mathrm{~cm} / \mathrm{h}$. The bound species were eluted with a buffer containing $20 \mathrm{mM}$ Tris, $10 \mathrm{mM}$ EDTA, $1 \mathrm{M} \mathrm{NaCl}$ at $\mathrm{pH} 7.2$ in a linear gradient (20/30 $\mathrm{CV})$. All the fractions collected during chromatography were pooled according to the chromatograms and were further analyzed using the NanoDrop procedure and / or and agarose gel electrophoresis (see below). The amount of plasmid DNA bound was determined using the $50 \%$ breakthrough volume $(\mathrm{V})$, column void volume $\left(\mathrm{V}_{0}\right)$, initial pDNA concentration $\left(\mathrm{C}_{0}\right)$, and the column volume $(\mathrm{CV})$, as shown in Equation 1.

$$
\operatorname{DBC}(\mathrm{mg} / \mathrm{mL})=\frac{\mathrm{C}_{0} \times\left(\mathrm{V}-\mathrm{V}_{0}\right)}{\mathrm{CV}}
$$

A measure of the ion-exchange capacity of adsorbents was obtained using transient $\mathrm{pH}$ measurements ${ }^{24}$. Utilising this method, ionic capacities of $403 \mathrm{mmol} / \mathrm{L}$ and $119 \mathrm{mmol} / \mathrm{L}$ were measured for CG-DEAE fibers and GIR-DEAE Cryogel, respectively.

\section{DNA/RNA concentration determination and agarose gel electrophoresis}

All the pDNA loads and pooled fraction concentrations were determined using the NanoDrop 2000 procedure mentioned before. One OD unit at $260 \mathrm{~nm}$ in a $10 \mathrm{~mm}$ cuvette was assumed to correspond to a concentration of $50 \mu \mathrm{g} / \mathrm{mL}$ of dsDNA. The pDNA load and the fractions collected after chromatography were additionally analyzed using $0.8 \%$ agarose gel electrophoresis in TAE (40 mM Tris, $20 \mathrm{mM}$ acetic acid, $1 \mathrm{mM}$ EDTA, pH 8.0). A $1 \mathrm{~kb}$ Plus DNA ladder was used as a marker. The electrophoresis was carried out at $80 \mathrm{~V}$ for 1 hour and then stained with ethidium bromide for $30 \mathrm{~min}$.

\section{Results and discussion}

Large scale purification of pharmaceutical-grade pDNA is generally based on the adsorption capacity and reversibility, where two limitations need to be overcome. Firstly, large biomolecules, like pDNA, possess low diffusion coefficients and display slow binding 
kinetics $^{22}$. Hence, it is advantageous to use convective media for their purification. Secondly, they need large pores with high interconnectivity such that molecules can penetrate easily into the interior part of the bead structure. Monoliths and membranes are the best options to overcome these limitations. In contrast to conventional media, monoliths have a continuous porous structure with a convective flow regime of the mobile phase. Furthermore, the large pore diameters of the monolithic column allow for better mass transfer in the case of larger bioparticles $^{16,24}$.

The production of novel chromatography adsorbents is an ever-evolving field. The advances in cell and life sciences produce an expanding variety of biotechnolgy-derived products. And ont every product can be easily hadled with existing purification platforms. In this context, research has been gered towards a) the development of new or improved adsorbents (to expand applications to emerging product niches) and b) the development of new processing schemes (to extend the life cycle of existing adsorbents). In the specific case of pDNA, initial attempts to purify such product with existing (and diffusion controlled) beaded adsorbents were unsecsesfull. However, initial studies found that binding of pDNA was pellicular in nature; very large macromolecules are excluded from traditional chromatography beads. Nowadys, convective-flow commercial adsorbents exist (CIM / BIA, Ajdova ina, Slovenia). Since these systems offer limited scale-up capabilities, industrial users take advantage of the high capacity of beaded adsorbents (CaptoAdhere / GE, Uppsala, Sweden) and utilized them in the "negative" mode (i.e. impurities are trapped by the adsorbent while the product is found in the flow-through).

In the mentioned context, we have evaluated materials other than the ones mentioned above; these are well known in the market. In our approach, a NW fiber network, as well as, a cryogel-type backbone were modified to harbor epoxide functionality. This was performed by grafting with a single vinyl-containing monomer such as GMA and two modes of initiators, physical and chemical. Finally, pendant epoxy groups were modified to provide weak anion-exchange functionality ${ }^{9}{ }^{23}$. The (dynamic) binding capacity of the composite anion exchange, high voidage, adsorptive systems was investigated for pDNA purification. In this work, the use of RNase for reducing RNA impurities was avoided as they further 
complicate the purification process by adding an additional step for the removal of RNase from the plasmid extract.

Reversible binding of pDNA (generated from E. coli cells) onto grafted adsorbents was determined by eluting the adsorbed pDNA with a linear gradient elution using $20 \mathrm{mM}$ Tris- $\mathrm{HCl}$ buffer containing 2.0 M sodium chloride. Plasmid DNA capacity was determined by quantifying the amount bound to the adsorbents according to Equation 1. The chromatographic purification was performed using 20 mM Tris-HCl, 10 mM EDTA, pH 7.4, where pDNA load conductivity was adjusted using equilibration to $25-28 \mathrm{mS} / \mathrm{cm}$, and the bound pDNA was eluted using $1.0 \mathrm{M}$ sodium chloride in $20 \mathrm{mM}$ Tris-HCl. The dynamic binding capacity (from eluted fractions) for CG-DEAE-NW (fibrous) and GIR-DEAE-MP (cryogel-type) was $2.4 \mathrm{mg} / \mathrm{mL}$ and $1.3 \mathrm{mg} / \mathrm{mL}$, respectively. The chromatographic profiles for different adsorbents can be observed in Figure 1a and 1b. From the agarose gel electrophoresis (Figure 2a and 2b) it is clear that RNA is co-eluted with pDNA, which may contribute the low pDNA binding capacities. This effect could be alleviated by a "negative" chromatography capture of small contaminants (e.g. RNA) immediately upstream -which can be based on traditional (beads) or alternative (fibrous) adsorbents.

Our preparation depicts an abundant presence of RNA in the crude pDNA load. As mentioned, removal of RNA impurities from the pDNA presents a genuine challenge in the production of gene therapy products. In the case of fibrous adsorbents, a low capacity for pDNA could result from a combination of competition and exclusion effects. pDNA preferentially bind to the internal surface of the megaporous structure. And internal surface is, in turn limited by geometrical considerations. It is interesting to note that the same adsorbents showed a very reasonable capacity for model proteins (for example, BSA) indicating that functionaly is present. In a nutshell, pDNA capacity values $(50 \%$ breakthoruth) were in the reange of $1.20 \mathrm{mg} / \mathrm{mL}$ to $2.50 \mathrm{mg} / \mathrm{mL}$ ). This is higher (Table 1) than the capacity observed in commercial Q and DEAE Sepharose FF resins. However, composite adsorbents showed lower capacities when compared to the CIM-DEAE monoliths, which have been extensively used for the large-scale purification of $\mathrm{pDNA}^{25}$. 
These experiments indicate that "expanded" adsorbents of the type studied in this work still present a significant binding capacity for pDNA having a molecular weight $>1750$ $\mathrm{kDa}$; these data add to our knowledge on this completely new class chromatography modality. All in all, composite adsorbents could be further developed to serve the purpose of primary, intermediate or late-stage purification.

\section{Conclusions}

In this study, we have evaluated the performance of DEAE-based composite adsorbents in relation to their ability to reversely capture (and purify) a large macromolecular entity (sc pDNA). The performance of the expanded DEAE system was assessed by saturating the "column" with a clarified lysate solution. The product were eluted by increasing the salt concentration. These anion-exchange adsorbents showed promising binding capacity at moderate-high flow rates. A less desirable feature observed of the new anion exchange was a limited capacity when compared to benchmark commercial products. For excluded macromolecules there is an obvious compromise between internal surface are and the total degree of porosity within the material. Further studies are needed to explore other types of composites and to understand the performance limits of this type of materials.

\section{Acknowledgements}

The authors thank Generi Biotech for generously providing the plasmid DNA. This work is funded by the European Union Seventh Framework Programme (FP7/2007-2013) under grant agreement no. 312004 .

The authors have declared no conflict of interest. 


\section{References:}

1. Prazeres DMF, Schluep T and Cooney C, Preparative purification of supercoiled plasmid DNA using anion-exchange chromatography. $J$ Chromatogr A 806: 31-45 (1998).

2. Li LZ, Liu Y, Sun MS and Shao YM, Effect of salt on purification of plasmid DNA using size-exclusion chromatography. J Chromatogr A 1139: 228-235 (2007).

3. Cardoso S, ernigoj U, Lendero Krajnc $\mathrm{N}$ and 'trancar A, Chromatographic purification of plasmid DNA on hydrophobic methacrylate monolithic supports. Sep Purif Technol 147: 139-146 (2015).

4. Diogo MM, Queiroz JA, Monteiro GA, Martins SAM, Ferreira GNM and Prazeres DMF, Purification of a cystic fibrosis plasmid vector for gene therapy using hydrophobic interaction chromatography. Biotechnol Bioeng 68: 576-583 (2000).

5. Colote S, Ferraz C and Liautard JP, Analysis and purification of plasmid DNA by reversed-phase high-performance liquid chromatography. Analytical biochemistry 154: 15-20 (1986).

6. Potter OG, Breadmore $\mathrm{MC}$ and Hilder $\mathrm{EF}$, Boronate functionalised polymer monoliths for microscale affinity chromatography. Analyst 131: 1094-1096 (2006).

7. Tiainen P, Galaev I and Larsson PO, Plasmid adsorption to anion-exchange matrices: comments on plasmid recovery. Biotechnology journal 2: 726-735 (2007).

8. Urthaler J, Buchinger $\mathrm{W}$ and Necina R, Industrial scale cGMP purification of pharmaceutical grade plasmid-DNA. Chem Eng Technol 28: 1408-1420 (2005).

9. $\quad$ Singh NK, Dsouza RN, Grasselli M and Fernandez-Lahore M, High capacity cryogeltype adsorbents for protein purification. J Chromatogr A 1355: 143-148 (2014).

10. Lozinsky VI, Galaev IY, Plieva FM, Savina IN, Jungvid H and Mattiasson B, Polymeric cryogels as promising materials of biotechnological interest. Trends Biotechnol 21: 445-451 (2003).

11. Singh NK, DSouza RN, Bibi NS and Fernández-Lahore M, Direct Capture of His6Tagged Proteins Using Megaporous Cryogels Developed for Metal-Ion Affinity Chromatography, in Affinity Chromatography: Methods and Protocols, ed by Reichelt S. Springer New York, New York, NY, pp. 201-212 (2015).

12. Bibi NS, Singh NK, Dsouza RN, Aasim M and Fernandez-Lahore M, Synthesis and performance of megaporous immobilized metal-ion affinity cryogels for recombinant protein capture and purification. J Chromatogr A 1272: 145-149 (2013).

13. Eon-Duval A and Burke G, Purification of pharmaceutical-grade plasmid DNA by anion-exchange chromatography in an RNase-free process. Journal of Chromatography B 804: 327-335 (2004). 
14. Schleef M, Issues of Large-Scale Plasmid DNA Manufacturing, in Biotechnology Set, ed by Rehm H-J and Reed G. Wiley-VCH Verlag GmbH, Weinheim, Germany, pp. 443-469 (2008).

15. Branovic K, Forcic D, Ivancic J, Strancar A, Barut M, Kosutic Gulija T, Zgorelec R and Mazuran R, Application of short monolithic columns for fast purification of plasmid DNA. J Chromatogr B 801: 331-337 (2004).

16. Singh N, Dsouza RN, Grasselli M and Fernandez-Lahore M, Gamma ray-mediated functionalization of monolithic cryogels for macro-biomolecule purification. New Biotechnol 31: S127-S127 (2014).

17. Podgornik A, Jancar J, Merhar M, Kozamernik S, Glover D, Cucek K, Barut M and Strancar A, Large-scale methacrylate monolithic columns: design and properties. $J$ Biochem Biophys Methods 60: 179-189 (2004).

18. Bencina M, Podgornik A and Strancar A, Characterization of methacrylate monoliths for purification of DNA molecules. J Sep Sci 27: 801-810 (2004).

19. Teeters MA, Root TW and Lightfoot EN, Adsorption and desorption behavior of plasmid DNA on ion-exchange membranes. Effect of salt valence and compaction agents. J Chromatogr A 1036: 73-78 (2004).

20. Franco-Medrano DI, Guerrero-Germán P, Montesinos-Cisneros RM, Ortega-López J and Tejeda-Mansir A, Plasmid pVAX1-NH36 purification by membrane and bead perfusion chromatography. Bioprocess and Biosystems Engineering 40: 463-471 (2017).

21. Silva-Santos AR, Alves CPA, Prazeres DMF and Azevedo AM, A process for supercoiled plasmid DNA purification based on multimodal chromatography. Sep Purif Technol 182: 94-100 (2017).

22. Prazeres DMF, Prediction of diffusion coefficients of plasmids. Biotechnol Bioeng 99: 1040-1044 (2008).

23. Singh NK, Dsouza RN, Sanchez ML, Verma S, Achilli E, Vennapusa RR, Grasselli $\mathrm{M}$ and Fernandez-Lahore M, Preparation and characterization of grafted cellulosic fibers and their applications in protein purification. Sep Purif Technol 143: 177-183 (2015).

24. Gavara P, Bibi N, Sanchez M, Grasselli $M$ and Fernandez-Lahore M, Chromatographic Characterization and Process Performance of Column-Packed Anion Exchange Fibrous Adsorbents for High Throughput and High Capacity Bioseparations. Processes 3: 204 (2015).

25. Smrekar F, Podgornik A, Ciringer M, Kontrec S, Raspor P, Štrancar A and Peterka M, Preparation of pharmaceutical-grade plasmid DNA using methacrylate monolithic columns. Vaccine 28: 2039-2045 (2010). 


\section{Figure captions}

Figure 1. a) pDNA capture onto CG-DEAE fibers at $300 \mathrm{~cm} / \mathrm{h}$. Conditions: Stationary phase: $1 \mathrm{~mL}$ of column volume; Load: $400 \mathrm{~mL}$ pDNA $(100 \mu \mathrm{g} / \mathrm{mL})$; equilibration buffer: $50 \mathrm{mM}$ Tris-HCl, 10 mM EDTA, $300 \mathrm{mM} \mathrm{NaCl}$, pH 7.4; washing buffer - $50 \mathrm{mM}$ Tris-HCl, $10 \mathrm{mM}$ EDTA, pH 7.4; elution buffer - 50 mM Tris-HCl, 10 mM EDTA, $1 \mathrm{M} \mathrm{NaCl}, \mathrm{pH}$ 7.4; flow rate: $1 \mathrm{~mL} / \mathrm{min}$; UV detection at 260 and $280 \mathrm{~nm}$. b) pDNA capture onto GIR-DEAE cryogels at $300 \mathrm{~cm} / \mathrm{h}$. Conditions: Stationary phase: $2.7 \mathrm{~mL}$ of column volume; Load: $200 \mathrm{~mL}$ pDNA (100 $\mu \mathrm{g} / \mathrm{mL})$; equilibration buffer: $50 \mathrm{mM}$ Tris-HCl, $10 \mathrm{mM}$ EDTA, $300 \mathrm{mM} \mathrm{NaCl}, \mathrm{pH}$ 7.4; washing buffer - $50 \mathrm{mM}$ Tris-HCl, $10 \mathrm{mM}$ EDTA, $\mathrm{pH}$ 7.4; elution buffer - $50 \mathrm{mM}$ Tris- $\mathrm{HCl}$, $10 \mathrm{mM}$ EDTA, $1 \mathrm{M} \mathrm{NaCl}$, $\mathrm{pH}$ 7.4; flow rate: $4 \mathrm{~mL} / \mathrm{min}$; UV detection at 260 and $280 \mathrm{~nm}$.

Figure 2. Agarose gel electrophoresis of pDNA captured using grafted adsorbents. (a) CGDEAE fibers; Lane M shows DNA Ladder, Lane L shows pDNA load, Lane LFT shows load flow through, Lane WFT shows wash flow through, Lane P1 (2 fractions)-P2 (2 fractions) shows elution profiles. (b) GIR-DEAE cryogels; Lane M shows DNA Ladder, Lane L shows pDNA load, Lane LFT shows load flow through, Lane WFT shows wash flow through, Lane $\mathrm{P} 1-\mathrm{P} 4$ shows elution profiles. 
a)

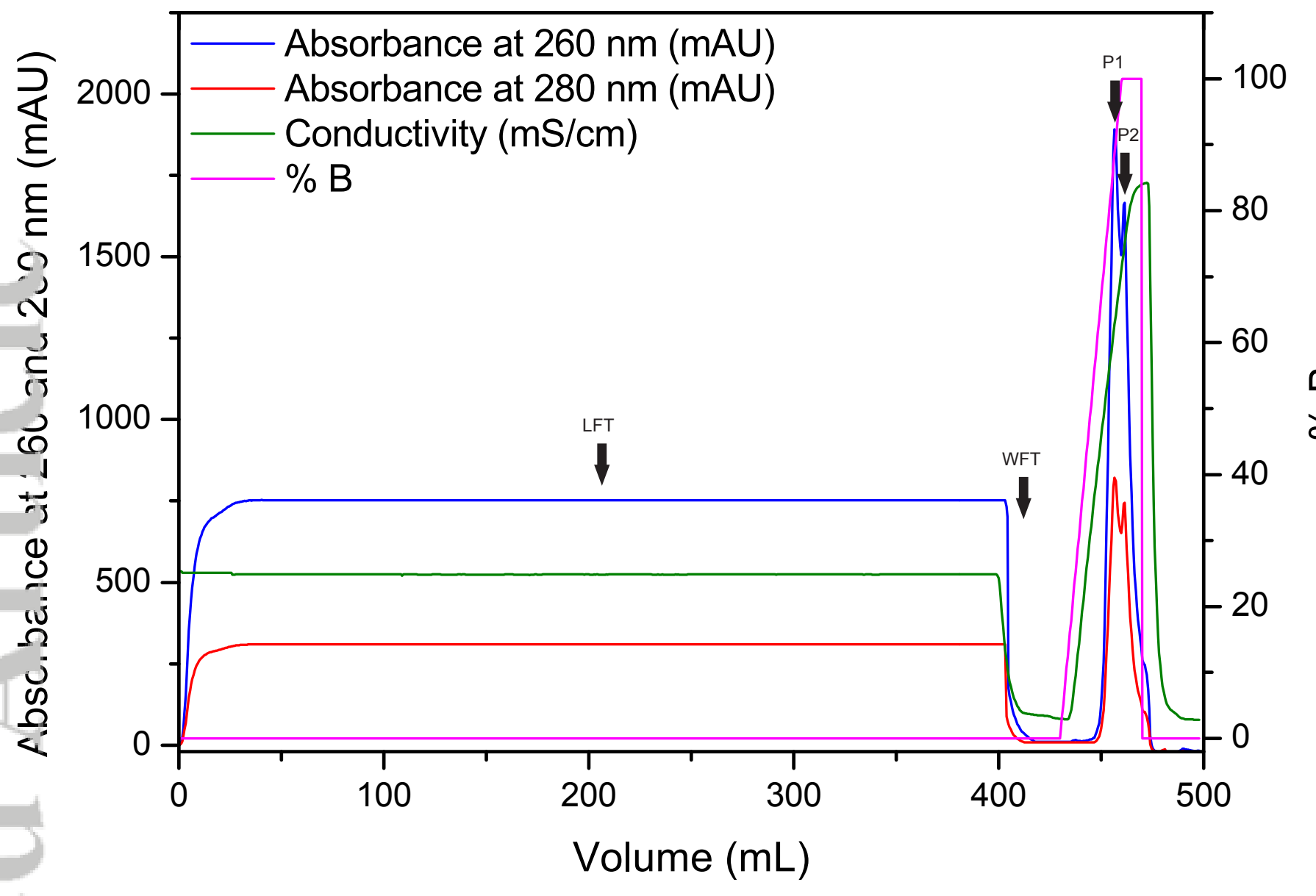

b)

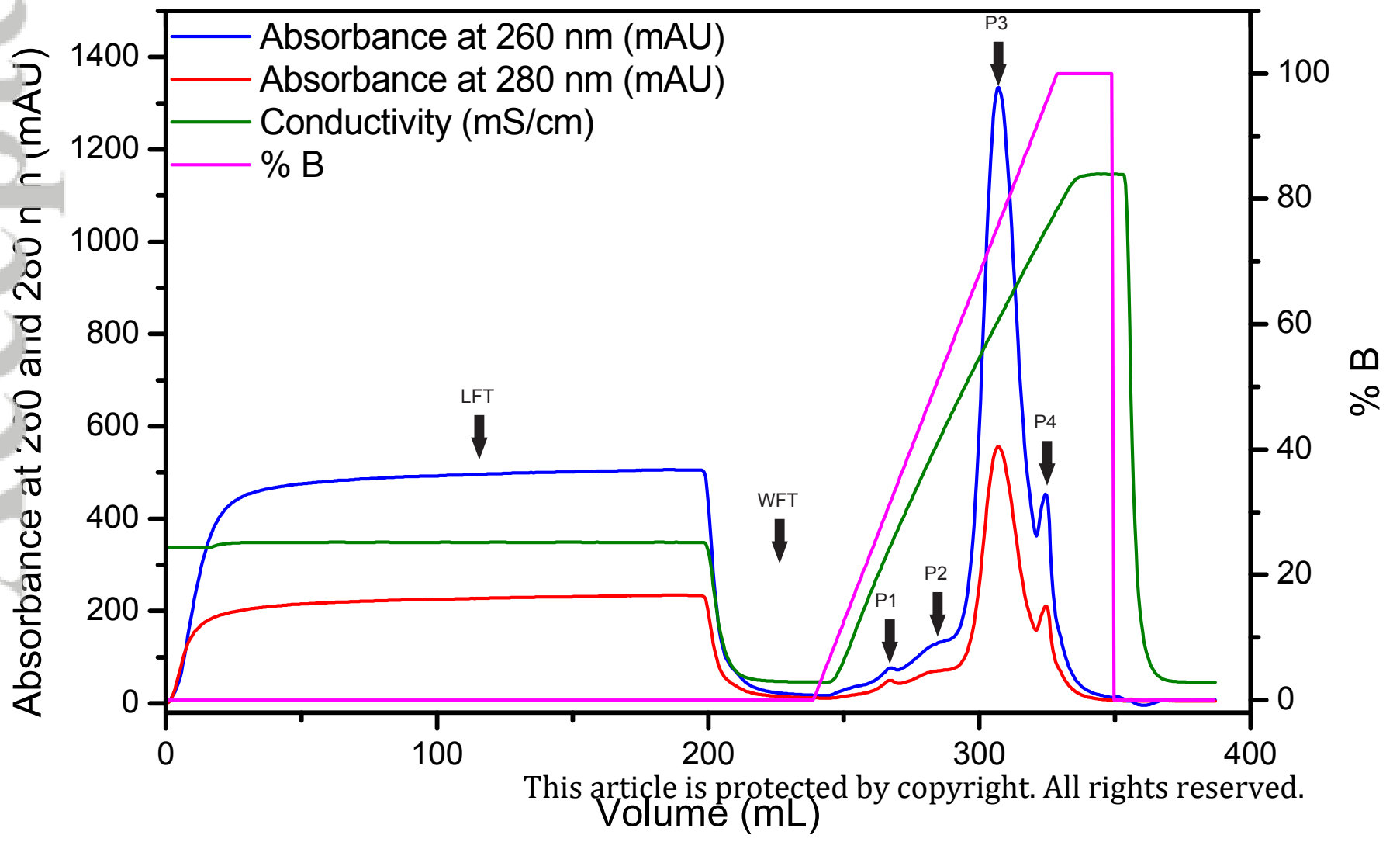




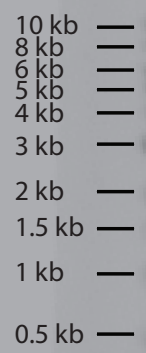

oc pDNA

sc pDNA

RNA

M L LFT WFT P1 P2

P3

P4

oc PDNA sc pDNA

RNA

This article is protected by cc 


\section{Tables with Captions}

Table 1: Comparison of dynamic binding capacities of CG and GIR.

\begin{tabular}{lc}
\hline Adsorbents & $\begin{array}{c}\text { Capacity } \\
(\mathrm{mg} / \mathrm{mL})\end{array}$ \\
\hline CG-DEAE fibers & 2.4 \\
GIR-DEAE cryogels & 1.3 \\
DEAE Sepharose FF [59] & 0.26 \\
Toyopearl DEAE 650 M [59] & 0.39 \\
Q Sepharose FF [60] & 0.72 \\
Fratogel-DEAE [60] & 2.45 \\
Q Ceramic HyperD 20 [59, 60] & $>2.5$ \\
CIM-DEAE [61] & $6-8$
\end{tabular}

CG stands for chemical grafting; GIR is gamma irradiation; Flow rate $-300 \mathrm{~cm} / \mathrm{h}$. 